\title{
anatomy
}

Teaching Anatomy

www.anatomy.org.tr

Received: May 19, 2019; Accepted: Fuly 6, 2019

doi:10.2399/ana.19.054

\section{Contribution of 3D modeling to anatomy education: a pilot study}

\author{
Hale Öktem ${ }^{1}$ (D), Tuğçe Şençelikel ${ }^{2}$ (D) , Ece Akçiçek ${ }^{3}$ (D), A. Sena Koçyiğit' ${ }^{3}$ (D), U. Sena Penekli ${ }^{3}$ (D), \\ Sezin Sungur ${ }^{3}$ (D), Beste Tanriyakul ${ }^{3}$ (iD, Başak Naz Ulusoy ${ }^{3}$ (D) \\ ${ }^{1}$ Department of Anatomy, School of Medicine, Başkent University, Ankara, Turkey \\ ${ }^{2}$ Department of Biostatistics, School of Medicine, Başkent University, Ankara, Turkey \\ ${ }^{3}$ Term III Student, School of Medicine, Başkent University, Ankara, Turkey
}

\begin{abstract}
Objectives: Traditional anatomy education involves theoretical lectures and practical applications, including examination of cadavers and models. In recent years, new technologies in biomedical fields have included three-dimensional (3D) modeling techniques that enable rapid creation of a 3D computer version of physical models. Such 3D modeling can be used as an active educational tool that enables students to better understand organs and how these organs are positioned relative to one another in anatomy education. The aim of this study was to analyze how the active role and involvement of students in 3D modeling contributes to anatomy education and 3D thinking.

Methods: In this study, 29 Term II students studying in the Başkent University School of Medicine were enrolled with 3D modeling training based on an anonymized CT sample. In addition to defining anatomic structures observed in the sections, 3D images of the common carotid artery, thyroid gland and trachea were obtained using the TT3D-BMMP software, and the position of these structures relative to one another was evaluated. The results of the anatomy quizzes given before and after the 3D modeling training were statistically evaluated.

Results: A statistically significant difference was found between the results of the quizzes administered before and after the training $(p<0.001)$. However, no statistically significant difference was found between male and female students in terms of the quiz results before training, while a significant difference was found in the quiz results after training.

Conclusion: We believe that sectional and radiological identification and recognition of anatomical structures by the students through 3D modeling will facilitate their anatomy education and be beneficial in terms of clinical practices in the future.
\end{abstract}

Keywords: 3D modeling; anatomy; education

Anatomy 2019;13(2):116-121 C2019 Turkish Society of Anatomy and Clinical Anatomy (TSACA)

\section{Introduction}

As the oldest field of medicine, anatomy examines the normal shape and structure of the body, the organs that form the body, and the structural and functional relationships between these organs. The primary educational tools used in anatomy education include theoretical books, atlases, plastinated or embalmed cadavers, and digital pictures. ${ }^{[1-5]}$

Spatial ability is important in learning anatomy. Understanding the spatial and visual relationships of anatomical structures with one another forms the basis of the anatomy training. ${ }^{[6]}$ Furthermore, modern technology offers various solutions in at least acquiring certain types of resources. Among the new technologies that have been introduced in the recent years into the biomedical fields for research, practice and education purposes are the fast prototyping techniques used in three dimensional (3D) printing. ${ }^{[7]}$ With using 3D software, students can visualize visceral organs and determine variations of these organs. ${ }^{[8,9]}$

This study was an oral presentation at the XXI Students Symposium of Study Modules, May 22-24, 2019, Ankara, Turkey. 
Moreover, in certain faculties of medicine, reaching the resources used in anatomy education can be difficult not only due to a lack of financial resources, but also for ethical, legally and cultural reasons. It is considered that the new opportunities provided by modern technology can create a path for overcoming these difficulties. ${ }^{[7]}$

Anatomical models are important during academic education, and are also used today in clinic practice as well. ${ }^{[10]}$ With the use of $3 \mathrm{D}$ modeling technology in clinics, it becomes possible to perform modeling specifically for a single patient, and to intervene on the patient in the most suitable manner by developing the necessary strategies for surgery. ${ }^{[1]}$

A 3D modeling can quickly create a 3D computer version of a physical model. In the recent years, 3D modeling applications have started to be used in medicine, medical education, diagnosis, surgery planning and bone reconstructions. ${ }^{[12]}$

Moreover, 3D anatomy software is beneficial for the students' self-learning. This software is also relevant for the courses on cadaver dissection, which are provided under the guidance of instructors. The development of a computer-based anatomy education supports students in adapting and implementing their anatomy knowledge in real life. ${ }^{[13]}$ The $3 \mathrm{D}$ modeling and the two-dimensional radiological imaging methods (such as cross-sectional anatomy, MR and CT) that students practice during their basic medical education allow them to gain prior experience in clinical applications.

The objective of this study was to evaluate the contribution of 3D modeling on the active role and involvement of students in anatomy education and on their ability to imagine in three dimensions. Furthermore, in the light of the results, it can give an idea about whether computer based education system should be included in medical curriculum.

In this study, 3D modeling of thyroid gland was performed. The thyroid gland is the largest endocrine gland located in the anterior part of the neck, below and lateral to the thyroid cartilage, consisting of an isthmus with two lateral lobes on the right and left. The isthmus neighbors the second and third tracheal rings on their anterior side, while the sternohyoid, sternothyroid and omohyoid muscles are located in front of the isthmus. The thyroid gland is supplied by superior and inferior thyroid arteries. Recurrent laryngeal nerves pass under the medial surface of the lateral lobes. ${ }^{[14]}$ The anatomical neighborhood of the gland to the inferior thyroid artery and laryngeal nerve is important for complications that may occur during thyroid surgery. ${ }^{[15,16]}$

\section{Materials and Methods}

Our study was conducted with a total of 29 Term II students, including 17 women and 12 men from Başkent University School of Medicine. All of the students were given an anatomy quiz (the first quiz) 15 days after taking the theoretical anatomy lecture of endocrine organs. Then 29 students were trained with 3D modeling using the TT3D-BMMP method, and asked to perform a 3D modeling of the thyroid gland and the neighboring trachea and common carotid artery. They were not informed about a second quiz.

An anatomy quiz (the second quiz) that included the same questions was administered again 30 days after the modeling training was performed and the modeling activities were carried out. The anatomy quiz consisted of ten questions with ten slides that contained two dimensional atlas pictures, atlases, and cadaver and radiologic sections. In each slide, a question was asked about a structure. The post-exam assessment was performed by giving one point for each question. The scores of the exams prior to and after the training (the first and second quizzes) were statistically evaluated.

TT3D-BMMP software was used for the 3D modeling training. This software was developed by Dr. Erhan Kızıltan from Department of Biophysics in Başkent University School of Medicine. The students first performed the manual segmentation of the thyroid gland, common carotid artery and trachea from 60 sections of 1.5 $\mathrm{mm}$ thickness found in the CT scan of an anonymous patient (Figures 1-3).

Before and during the modeling training, standard information was given to the students regarding the structures observed in the sections. The structures segmented by the TT3D-BMMP software were distinguished by the students. A 3D mesh-structure (mesh) was formed, and then visualized with the GMESH software. The post-processing applications which were performed with this software was freely and easily available. The relation between the anatomical structures were also evaluated in three dimensions with the post-processing applications and compared in terms of appearance and size with ideal atlas images.

Descriptive statistics in the study were given as mean \pm standard deviations. The difference between the exam results before and after the training was analyzed using the paired sample $t$ test. By separately evaluating the exam results before and after the training, the difference between the gender groups was analyzed using the MannWhitney $\mathrm{U}$ test. In the analysis, the type I error probabil- 


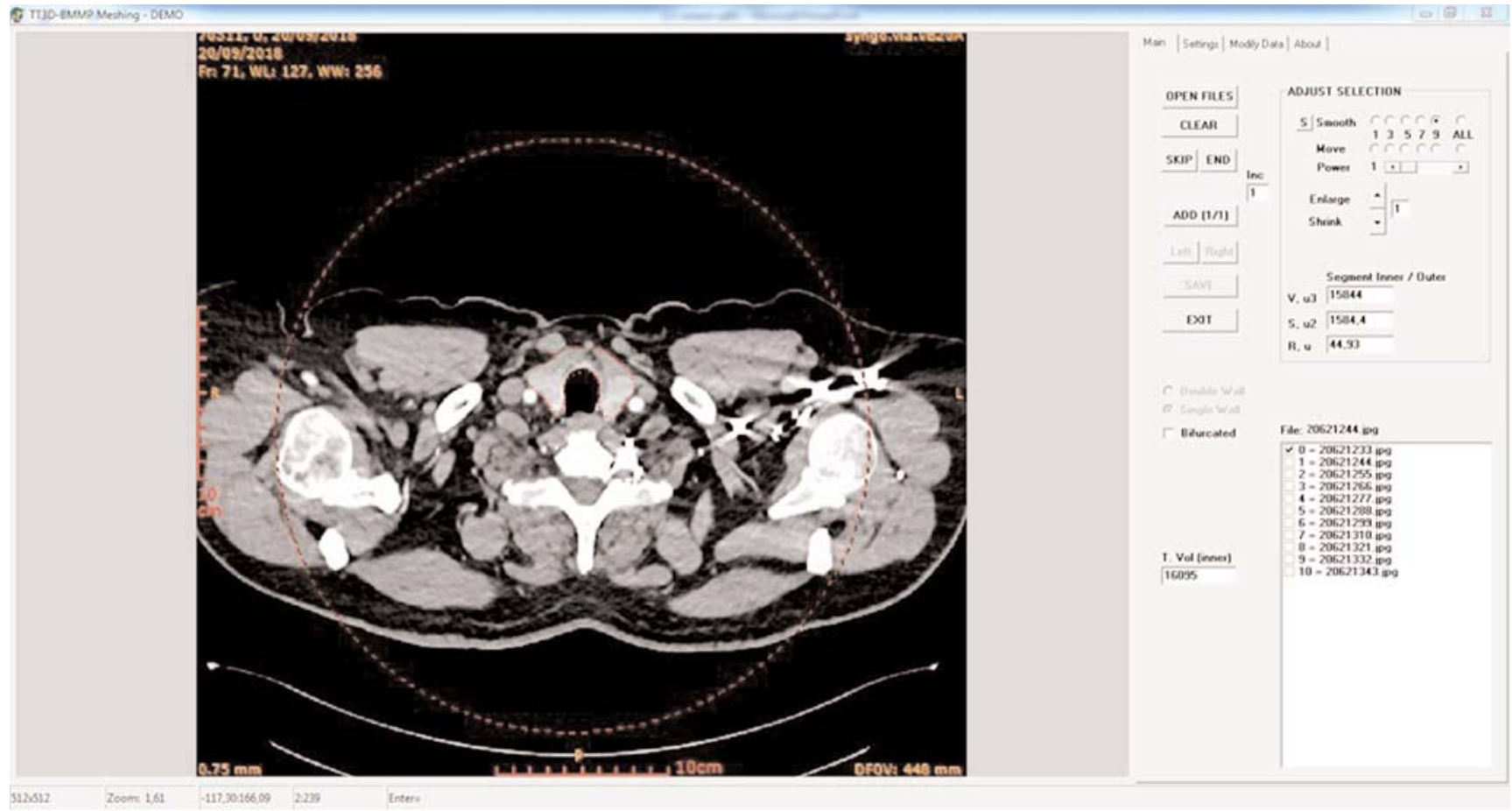

Figure 1. Segmentation of the thyroid gland.

ity was determined as 0.05 . All analyses were performed using IBM SPSS Statistics for Windows (Version 25, Armonk, NY, USA). This study was approved by the
Başkent University Medical and Health Sciences Research Committee (Project number: KA19/72) and supported by the Başkent University Research Fund.

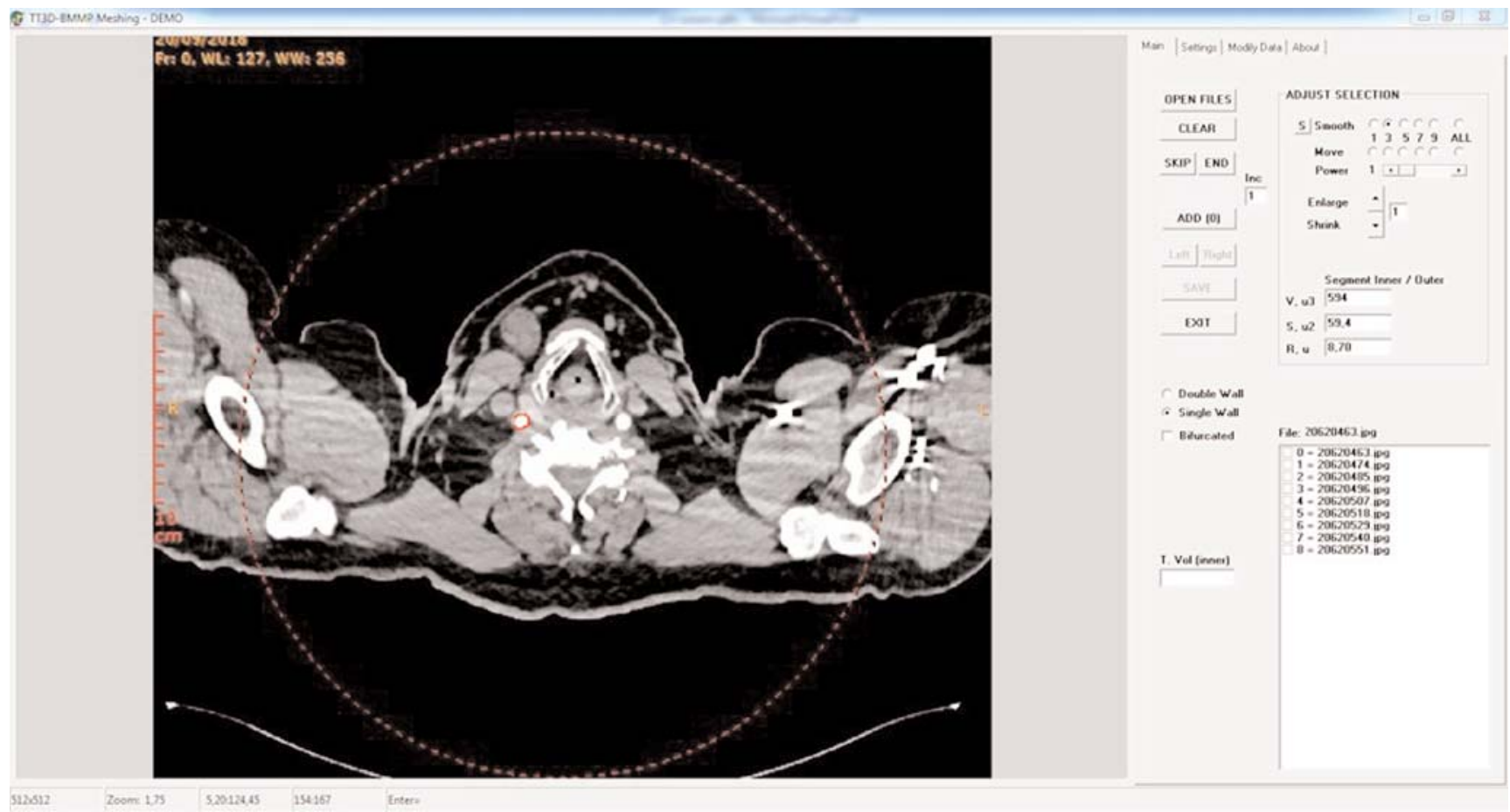

Figure 2. Segmentation of the common carotid artery. 


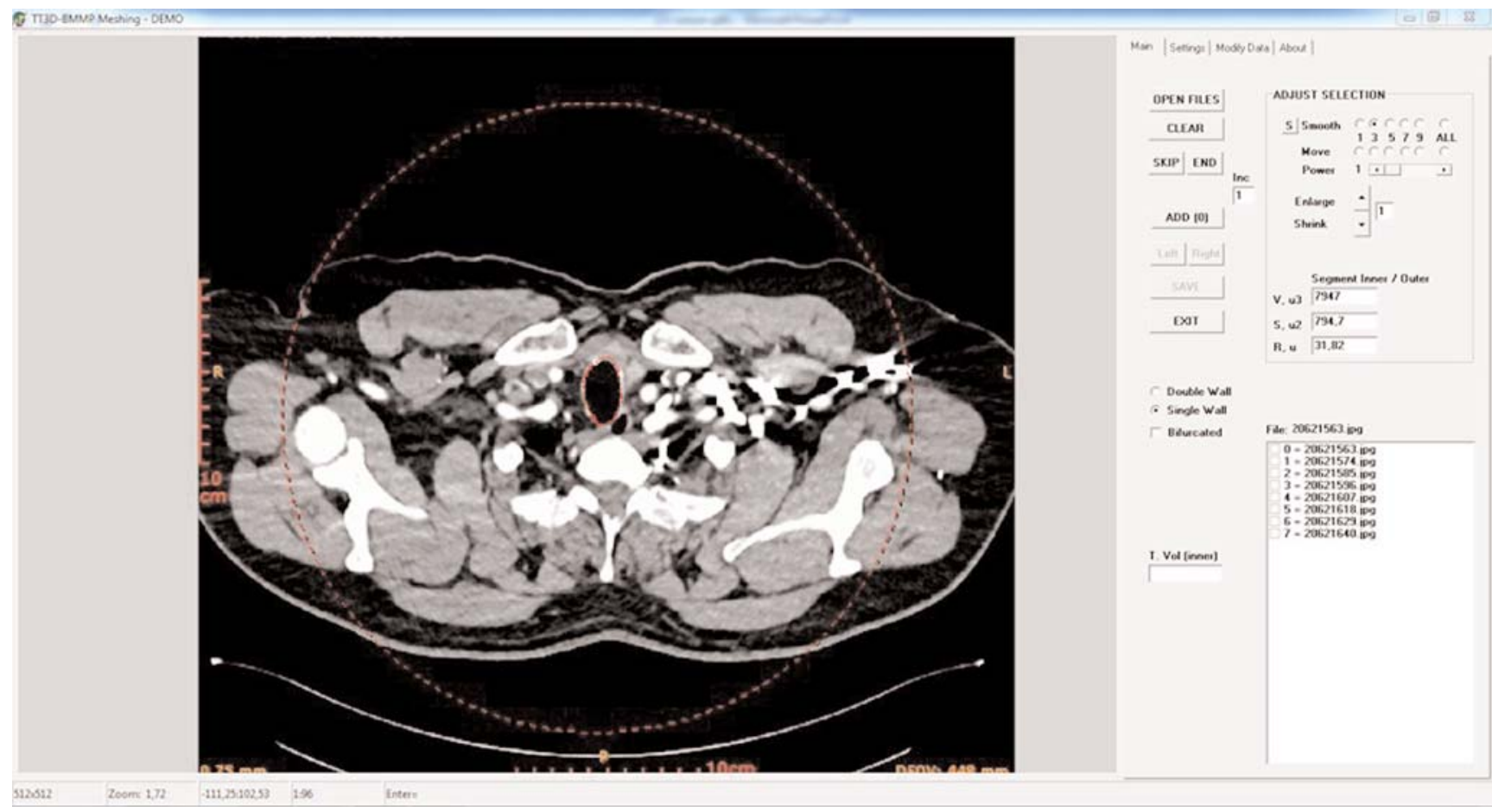

Figure 3. Segmentation of the trachea.

\section{Results}

Segmentations of the thyroid gland, trachea and common carotid artery were performed by the students using the TT3D-BMMP software, and mesh models were also prepared. One physical model was produced as a sample (Figures 4 and 5).

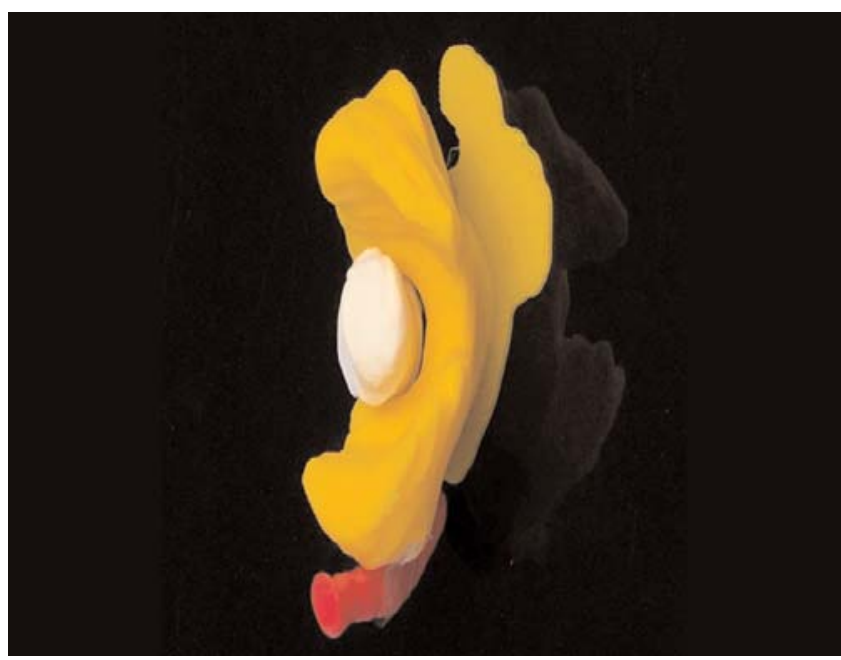

Figure 4. Superior view of 3D model of thyroid gland, common carotid artery and trachea. [Color figure can be viewed in the online issue, which is available at www.anatomy.org.tr]
The models were visually compared with radiography images and ideal atlas images in terms of appearance and scale. The anatomy quizzes given before and after the $3 \mathrm{D}$ modeling training were evaluated based on ten points, with each question having a value of one point. Descriptive statistics of the quizzes given before (first)

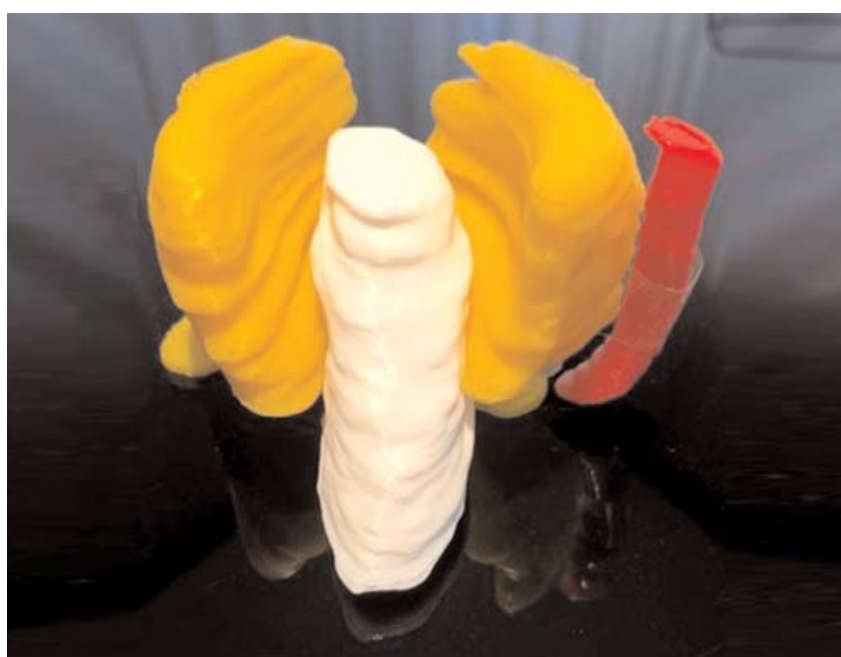

Figure 5. Posteror view of 3D model of thyroid gland, common carotid artery and trachea. [Color figure can be viewed in the online issue, which is available at www.anatomy.org.tr] 
Table 1

Descriptive statistics of quiz given before and after the 3D modeling training using paired sample t-test.

\begin{tabular}{lcc}
\hline Anatomy quiz & Mean \pm SD & $\mathbf{p}$ \\
\hline First quiz & $5.14 \pm 1.66$ & $<0.001$ \\
Second quiz & $7.10 \pm 1.37$ & \\
\hline
\end{tabular}

and after (second) the 3D modeling training are shown in Table 1.

A statistically significant difference was found between the first quiz given before the $3 \mathrm{D}$ modeling training and the second quiz given after the training $(\mathrm{p}<0.001)$. While the average score in the exam before the training was approximately 5 points, the average exam score increased to approximately 7 points after the training.

When the exam results were evaluated between the gender groups, no statistically significant difference was found between male and female students in terms of the first quiz results $(\mathrm{p}=0.873)$, while a significant difference was found in terms of the second quiz results $(\mathrm{p}=0.007)$

(Table 2).

\section{Discussion}

The results of this study showed that $3 \mathrm{D}$ modeling can be an effective method in anatomy education by allowing students to recognize structures in repeating segments and form 3D structures. Models printed with 3D modeling can also be used as materials in anatomy education. These models are also important in that they are individualized training materials and show variations.

Traditional learning model can be summarized as a $2 \mathrm{D} \rightarrow 3 \mathrm{D} \rightarrow 2 \mathrm{D}$ model. Information learned in such a manner makes it difficult to remember $3 \mathrm{D}$ structures correctly, and may even cause structures to be learned erroneously and deficiently. As was the case in this study, the $3 \mathrm{D}$ structures formed from consecutively repeating $2 \mathrm{D}$ sections through the integration of $3 \mathrm{D}$ modeling into $2 \mathrm{D}$ education has allowed for a more accurate and lasting learning. ${ }^{[17]}$

Table 2

Evaluation of first and second quiz results among genders using Mann-Whitney U test.

\begin{tabular}{lccc}
\hline & $\begin{array}{c}\text { First quiz } \\
\text { median (min-max) }\end{array}$ & $\begin{array}{c}\text { Second quiz } \\
\text { median (min-max) }\end{array}$ & $\mathbf{p}$ \\
\hline Women $(\mathrm{n}=17)$ & $5(1-8)$ & $7(4-9)$ & 0.873 \\
Men $(\mathrm{n}=12)$ & $5.5(2-7)$ & $8(7-9)$ & 0.007 \\
\hline
\end{tabular}

In a study by Vorstenbosch et al ${ }^{[6]}$ on spatial intelligence, students with high mental rotation test scores were also found to be more successful in the anatomy exam. Although men scored higher than women in both mental rotation tests, no significant gender-related increase was observed between the two tests. Similarly in this study, while the increase in the scores for men in the second exam after receiving the training was statistically significant $(\mathrm{p}=0.008)$, the increase in the score between the two exams was not found to be statistically significant for women $(\mathrm{p}=0.879)$.

Jamil et al. ${ }^{[18]}$ found that the scores of men were higher than women in both tests, and a significant increase was identified in the scores of both women and men. Although this study's objective was not to evaluate the difference between genders, it can be stated based on the obtained data that a statistically significant difference is present between the scores obtained in the two tests by male students.

Certain studies in the literature have aimed to provide training through a $3 \mathrm{D}$ model. In this study, our aim was to have the students learn anatomy by making $3 \mathrm{D}$ modeling from 2D sections. For example, in a previous study conducted on a 3D generated model, a comparison was made between groups that received traditional 2D education and 3D model education, and no difference was found between the two groups in terms of contribution to anatomy education. ${ }^{[19]}$

In another study by Lim et al. ${ }^{[20]}$ on $3 \mathrm{D}$ models, the cadaver samples group, the $3 \mathrm{D}$ models group and a group that combined the two were compared. While a significant improvement was observed in the results of the $3 \mathrm{D}$ model group no significant difference was observed in the other two groups. The use of $3 \mathrm{D}$ models instead of cadaver models does not create a disadvantage, and the results even demonstrate that the use of $3 \mathrm{D}$ model is more effective in anatomy education.

The development of spatial intelligence contributes to anatomy education, and anatomy education similarly contributes to the development of spatial intelligence in students. This mutual interaction positively affects the visual approach of the students towards their anatomy knowledge, making it easier for them to learn anatomy.

According to a study by Jamil et al., $97 \%$ of students found the use of 3D modeling software in education more effective as compared to plastic models. ${ }^{[18]}$ The use of 3D modeling in medical education will ensure greater visualization of dynamic processes in the mind, and allow for more effective use in both diagnosis and treatment in future. ${ }^{[21]}$ 
The low number of participants can be considered as a limiting factor of the present study. Since participation to the study was on a voluntary basis, the intense course schedule of medical students limited their participation in the study. The inability to distinguish nerves, certain small veins and certain muscles from soft tissues in every section when using different radiologic methods constitutes one of the difficulties of 3D modeling. ${ }^{[19]}$ This study represents a preliminary study; further studies are required for revealing its contribution to life-long learning.

\section{Conclusion}

By using such a $3 \mathrm{D}$ modeling program as a part of active education, students will improve themselves in evaluating the sectional images 3D manner. Such a program will make the students familiar to the localizations of different anatomical structures in the human body and their relations with each other. With the addition of $3 \mathrm{D}$ education into the curriculum, our aim was to increase the success of students in the anatomy class.

\section{Acknowledgements}

The authors wish to thank Erhan Kiziltan from Department of Biophysics, Faculty of Medicine, Başkent University for the TT3D-BMMP software.

\section{References}

1. Vaccarezza M. Best evidence of anatomy education? Insights from the most recent literature. Anat Sci Educ 2018;11:215-216.

2. Dinsmore CE, Daugherty S, Zeitz HJ. Teaching and learning gross anatomy. Clin Anat 1999;12:110-4.

3. Winkelmann A. Anatomical dissection as a teaching method in medical school: a review of the evidence. Med Educ 2007; 41:15-22.

4. Garas M, Vaccarezza M, Newland G. 3D-Printed specimens as a valuable tool in anatomy education: a pilot study. Ann Anat 2018; 219:57-66.

5. Bayko S, Yarkan İ, Çetkin M, Kutoğlu T. Views of medical students on anatomy education supported by plastinated cadavers. Anatomy 2018;12:90-6.

6. Vorstenbosch MA, Klaassen TP, Donders AR, Kooloos JG, Bolhuis SM, Laan RF. Learning anatomy enhances spatial ability. Anat Sci Educ 2013;6:257-62.

ORCID ID:

H. Öktem 0000-0002-2624-122X; T. Şençelikel 0000-0003-0364-0401; E. Akçiçek 0000-0003-0592-351X; A. S. Koçyiğit 0000-0002-6481-9168; U. S. Penekli 0000-0003-1516-1707; S. Sungur 0000-0003-3201-4602 B. Tanriyakul 0000-0002-0335-1522; B. N. Ulusoy 0000-0002-8351-0916
7. Abouhasem Y, Dayal M, Savanah Štrkalj G. The application of 3D printing in anatomy education. Med Educ Online 2015;20:29847.

8. Rehman FU, Khan SN, Yunus SM. Students, perception of computer assisted teaching and learning of anatomy - In a scenario where cadavers are lacking. Biomed Res 2012;23:215-8.

9. Cui D, Wilson TD, Rockhold RW, Lehman MN, Lynch JC. Evaluation of the effectiveness of $3 \mathrm{D}$ vascular stereoscopic models in anatomy instruction for first year medical students. Anat Sci Educ 2017;10:34-45.

10. Bücking TM, Hill ER, Robertson JL, Maneas E, Plumb AA, Nikitichev DI. From medical imaging data to 3D printed anatomical models. PLoS One 2017;12:e0178540.

11. Pugliese L, Marconi S, Negrello E, Mauri V, Peri A, Gallo V, Auricchio F, Pietrabissa A. The clinical use of 3D printing in surgery. Updates Surg 2018;70:381-8.

12. Krauel L, Fenollosa F, Riaza L, Pérez M, Tarrado X, Morales A, Gomà J, Mora J. Use of 3D prototypes for complex surgical oncologic cases. World J Surg 2016;40:889-94.

13. Venail F, Deveze A, Lallemant B, Lallemant B, Guevara N, Mondain M. Enhancement of temporal bone anatomy learning with computer 3D rendered imaging softwares. Med Teach 2010;32:e282-8.

14. Standring S (Editor). Gray's anatomy. 39th ed. Philadelphia, PA: Elsevier Churchill Livingstone; 2005.

15. Ozgur Z, Celik S, Govsa F, Ozgur T. Anatomical and surgical aspects of the lobes of the thyroid glands. Eur Arch Otorhinolaryngol 2011; 268:1357-63.

16. Ranade AV, Rai R, Pai MM, Nayak SR, Prakash, Krisnamurthy A, Narayana $S$. Anatomical variations of the thyroid gland: possible surgical implications. Singapore Med J 2008;49:831-4.

17. Lin C, Gao J, Zheng H, Zhao J, Yang H, Zheng Y, Cao Y, Chen Y, Wu G, Lin G, Yu J, Li H, Pan H, Liao Q, Zhao Y. When to introduce three-dimensional visualization technology into surgical residency: a randomized controlled trial. J Med Syst 2019;43:71.

18. Jamil Z, Saeed A, Madhani S, Baig S, Cheema Z, Fatima SS. Threedimensional visualization software assists learning in students with diverse spatial intelligence in medical education. Anat Sci Educ 2019; 12:550-60.

19. Wu AM, Wang K, Wang JS, Chen CH, Yang XD, Ni WF, Hu YZ. The addition of $3 \mathrm{D}$ printed models to enhance the teaching and learning of bone spatial anatomy and fractures for undergraduate students: a randomized controlled study. Ann Transl Med 2018;6:403.

20. Lim KH, Loo ZY, Goldie SJ, Adams JW, McMenamin PG. Use of $3 \mathrm{D}$ printed models in medical education: a randomized control trial comparing $3 \mathrm{D}$ prints versus cadaveric materials for learning external cardiac anatomy. Anat Sci Educ 2016;9:213-21.

21. Silén C, Wirell S, Kvist J, Nylander E, Smedby O. Advanced 3D visualization in student-centred medical education. Med Teach 2008;30: e115-24.

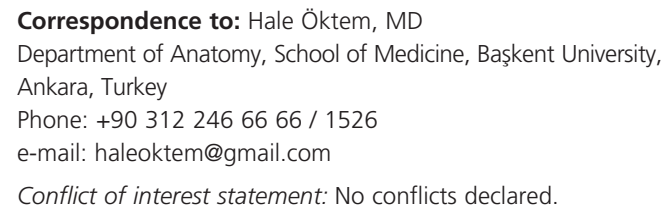

Conflict of interest statement: No conflicts declared.

This is an open access article distributed under the terms of the Creative Commons Attribution-NonCommercial-NoDerivs 3.0 Unported (CC BY-NC-ND3.0) Licence (http://creativecommons.org/licenses/by-nc-nd/3.0/) which permits unrestricted noncommercial use, distribution, and reproduction in any medium, provided the original work is properly cited. Please cite this article as: Öktem H, Şençelikel T, Akçiçek E, Koçyiğit AS, Penekli US, Sungur S, Tanriyakul B, Ulusoy BN. Contribution of 3D modeling to anatomy education: a pilot study. Anatomy 2019;13(2):116-121. 